\title{
The Sendai Framework for Disaster Risk Reduction: Renewing the Global Commitment to People's Resilience, Health, and Well-being
}

\author{
Amina Aitsi-Selmi ${ }^{1,2} \cdot$ Shinichi Egawa ${ }^{3}$ Hiroyuki Sasaki ${ }^{3}$. \\ Chadia Wannous $^{4} \cdot$ Virginia Murray $^{1,2,5}$
}

Published online: 16 June 2015

(C) The Author(s) 2015. This article is published with open access at Springerlink.com

\begin{abstract}
The Sendai Framework for Disaster Risk Reduction 2015-2030 (SFDRR) is the first global policy framework of the United Nations' post-2015 agenda. It represents a step in the direction of global policy coherence with explicit reference to health, development, and climate change. To develop SFDRR, the United Nations Office for Disaster Risk Reduction (UNISDR) organized and facilitated several global, regional, national, and intergovernmental negotiations and technical meetings in the period preceding the World Conference on Disaster Risk Reduction (WCDRR) 2015 where SFDRR was adopted. UNISDR also worked with representatives of governments, UN agencies, and scientists to develop targets and indicators for SFDRR and proposed them to member states for negotiation and adoption as measures of progress and achievement in protecting lives and livelihoods. The multiple efforts of the health community in the policy development process, including campaigning for safe schools and hospitals, helped to put people's mental and physical
\end{abstract}

Amina Aitsi-Selmi

Amina.Aitsi-Selmi@phe.gov.uk

1 Public Health Strategy Division, Public Health England, London SE1 8UG, UK

2 Research Department of Epidemiology and Public Health, University College London, London WC1E 6BT, UK

3 Division of International Cooperation for Disaster Medicine, International Research Institute of Disaster Science (IRIDeS), Tohoku University, Sendai 980-0845, Japan

4 The United Nations Office for Disaster Risk Reduction (UNISDR), Geneva, Switzerland

5 The United Nations Office for Disaster Risk Reduction (UNISDR) Scientific and Technical Advisory Group, Geneva, Switzerland health, resilience, and well-being higher up the disaster risk reduction (DRR) agenda compared with the Hyogo Framework for Action 2005-2015. This article reviews the historical and contemporary policy development process that led to the SFDRR with particular reference to the development of the health theme.

Keywords Disaster risk reduction - Global health $\cdot$ Health policy $\cdot$ Public health $\cdot$ Safe hospitals

\section{Introduction}

Disasters destroy lives and livelihoods around the world. Between the years 2000 and 2012, it is estimated that over 700,000 people lost their lives; more than 1.5 billion people were affected by disasters in various ways, with women, children, and several other groups impacted disproportionately. Disaster impacts also set back hard-won economic development gains and affect all socioeconomic strata, societal institutions, and sectors in one way or another. The total economic loss was estimated to have exceeded USD 1.3 trillion over the 2000-2012 period (UNISDR 2013a).

Disasters are not natural events. They are endogenous to society and disaster risk arises when hazards interact with the physical, social, economic, and environmental vulnerabilities and exposure of populations (UNISDR 2013b). Many of the destructive hazards are natural in origin and include earthquakes and extreme weather events resulting in floods and droughts, which has resulted in disaster risk management policy being largely event driven. Therefore, the attention of the policy community has naturally fallen on the hazards and the related physical processes that result in disasters. 
Progress in disaster risk reduction (DRR) research has shown that it is often not the hazard that determines a disaster, but the vulnerability, exposure, and ability of the population to anticipate, respond to, and recover from its effects. A shift from pure hazard response to the identification, assessment, and ranking of vulnerabilities and risks (including their unequal distribution in populations) became critical (Department for International Development 2006). This shift in focus takes into account social factors shaping local populations' interpretation of risks and their thresholds for action (Eiser et al. 2012). The implication is that societal determinants of risk (through individual or collective agency and with the assistance of science and technology) can be identified and influenced to achieve better economic and social development trajectories (Scott et al. 2013).

The Sendai Framework for Disaster Risk Reduction 2015-2030 (SFDRR) was born from the need to ensure DRR policy reflects our evolved understanding of the complexity of disaster risk in the twenty-first century. Implementation calls for closer collaboration among all sectors including the health sector in order to prevent, prepare for, respond to, and recover from disasters that result from the highly interdependent and evolving risks to which we are exposed.

This article provides a brief summary of the history of UN-based frameworks for DRR, a reflection on the processes leading to these frameworks, and finally focuses on SFDRR. It discusses some of the reasons for and importance of having a strong health focus in SFDRR and the benefits of the close relationship that health has with the science and technology aspects in this framework. It offers ideas on how renewing the global commitment to people's resilience, health, and well-being can be enhanced by the implementation of SFDRR over the next 15 years.

\section{Landmark Policy Developments Led by the United Nations in Disaster Risk Reduction}

Providing assistance to disaster-affected populations is almost as old as international cooperation itself (Kamidohzono et al. 2015). A turning point came with the UN General Assembly (UN/GA)'s recognition of "the importance of reducing the impact of natural disasters for all people, and in particular for developing countries." This led to the designation of the 1990s as the International Decade for Natural Disaster Reduction (IDNDR 1994) in which "the international community, under the auspices of the United Nations, paid special attention to fostering international co-operation in the field of natural disaster reduction" (UNISDR 2012).
In 2000, the International Strategy for Disaster Reduction (UNISDR) was established following IDNDR of the 1990s. The UN/GA convened the second World Conference on DRR in Kobe, Hyogo, Japan 2005, which concluded the review of the Yokohama Strategy and its Plan of Action and the adoption of the Hyogo Framework for Action 2005-2015: Building the Resilience of Nations and Communities to Disasters (HFA) (UNISDR 2005) by 168 countries. The HFA outlined five priorities for action:

(1) Ensure that DRR is a national and a local priority with a strong institutional basis for implementation;

(2) Identify, assess, and monitor disaster risks and enhance early warning;

(3) Use knowledge, innovation, and education to build a culture of safety and resilience at all levels;

(4) Reduce the underlying risk factors;

(5) Strengthen disaster preparedness for effective response at all levels.

In the HFA, health was mentioned only three times in one paragraph (19) under Priority 4 (reduce the underlying risk factors) (UNISDR 2005, p. 11):

Integrate DRR planning into the health sector; promote the goal of "hospitals safe from disaster" by ensuring that all new hospitals are built with a level of resilience that strengthens their capacity to remain functional in disaster situations and implement mitigation measures to reinforce existing health facilities, particularly those providing primary health care.

This text focuses narrowly on hospitals and health facilities, overlooking the wider societal determinants of human health and well-being.

Around the same time, two further global policy processes were initiated in parallel to the HFA process: the climate change agreements and Millennium Development Goals. The three policy areas were intricately related as they all draw on scientific knowledge and influence human well-being directly or indirectly. However, they were not linked together as clearly as they could have been in the HFA and the policy processes for each area developed as separate policy streams (Fig. 1). The economic development, emergency response, and climate change communities of research, policy, and practice are composed of different individuals and disciplines and managed by different organizations with different funding streams that deepen the siloes in theory and practice, albeit with some degree of overlap that is increasingly recognized and reflected in the UN post-2015 agenda.

Yet, there are obvious synergies between the three policy areas that can be emphasized and strengthened to promote policy coherence and facilitate convergence of objectives in implementation (ICSU and ISSC 2015). For 


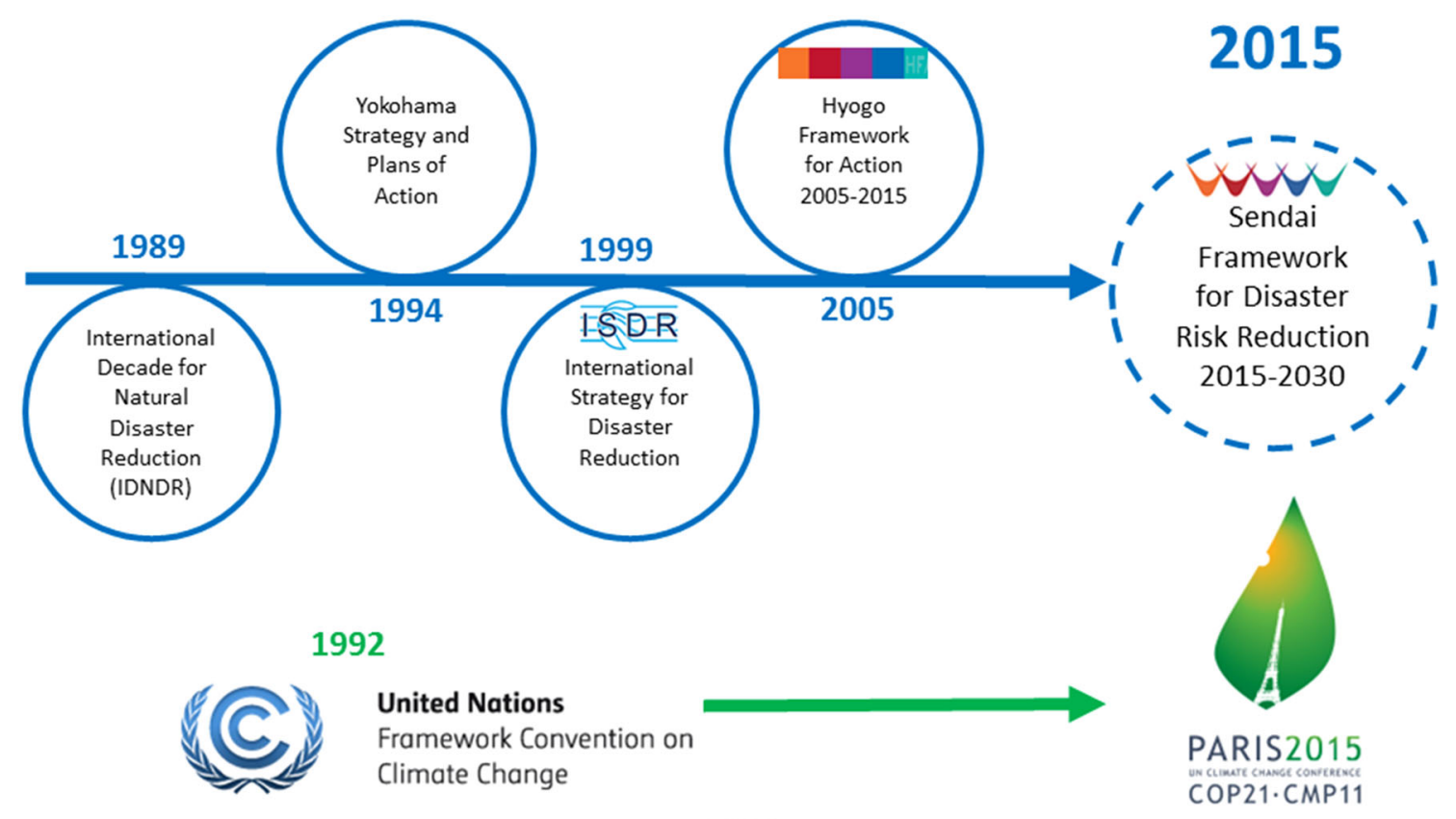

2000
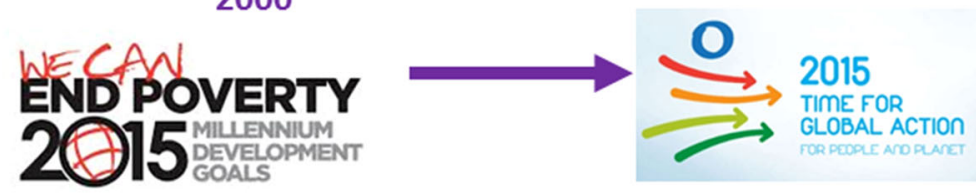

Fig. 1 Twenty five years of international commitments to disaster risk reduction [Source Adapted from presentation by Andrew Maskrey, Lead Author and Head of the Risk Knowledge (UNISDR 2015)]

example, important synergies that have not been realized exist between the proposed post-2015 sustainable development goals and the SFDRR targets and indicators: population health and well-being outcomes have been identified explicitly within the SDGs, but these cannot be achieved without managing those risks that are so closely associated with disasters such as weak critical infrastructure, for example, poorly built hospitals. The integration of climate change adaptation into planning and policy design, and decision making can promote support resilient economic development and prevention-orientated emergency planning.

Synergies with the climate change and sustainable development agenda should continue to be articulated and leveraged for more effective decision making and funding allocation. An all-hazard, risk-based, trans-disciplinary and multisectoral approach will help to identify and prioritize synergies, and this can help to formulate solutions to complex problems and the development of joint policy initiatives. This requires collaboration, communication, and capacity development across the scientific disciplines and technical fields, and with all stakeholders including representatives of governmental institutions, communities of policy making, scientific and technical specialists, the technology sector, and members of the communities at risk, in order to guide scientific research, set research agendas, and support education and training (Aitsi-Selmi et al. 2015).

This year-2015-presents an unparalleled opportunity to align landmark UN agreements through the convergence of three global policy frameworks: the Sendai Framework for DRR 2015-2030 (March 2015), the Sustainable Development Goals (September 2015; SDGs), and the Climate Change Agreements (December 2015; COP21). These major global policy instruments need to align urgently to facilitate and encourage better participation in DRR, sustainable development, and climate-change mitigation and adaptation from the science and technology communities.

\section{Public Health Needs in Disasters}

During recent decades, the world has faced a greater frequency and impact from disasters as well as a paradigm shift in the types of hazard and the possible risks that constitute a threat to human well-being, including climate change (see also Kelman 2015), rapid and unmanaged 
urbanization, lack of resources, poverty, and loss of biodiversity. The 2004 Indian Ocean earthquake and tsunami was historically exceptional in terms of its impact on lives and communities (Rodriguez et al. 2006). This disaster illustrated the vulnerability of multiple countries and communities to natural hazards that arise in distant locations. The event also encouraged the global community to adopt a comprehensive framework for action, and identify global priorities for work and practical steps that are required to achieve disaster resilience.

The implementation of the HFA over the past 10 years has been urged on by similar events, such as Hurricane Katrina, which served to remind society of the terrible consequences of limited planning and preparedness. Other examples include the 2011 East Japan Earthquake and Tsunami and Typhoon Haiyan in 2013, as well as the severe 2011 floods in Thailand that affected the Japanese car industry and the global computer industry for a significant period of time (Ye and Abe 2012).

The expansion of DRR to include risk assessments addressing vulnerability and exposure has been compared to the widening of health activities to include prevention which has traditionally been the preserve of public health. Public health is increasingly concerned with the total health system and not only the eradication of a particular disease affecting an individual patient (Murray et al. 2015). The consequences of disasters on human health and well-being are varied and include direct impacts on lives and livelihood sustainability and indirect impacts on macroeconomic growth and social support mechanisms (Schipper and Pelling 2006). The US Centers for Disease Control and Prevention link hazards to the transmission of infectious diseases, especially since water supplies and sewage systems may be disrupted and sanitation and hygiene may be compromised by population displacement and overcrowding that led to interrupted normal public health services (Malilay et al. 2013).

All three World conferences on DRR were held in Japan, which has been significantly affected by natural hazards but has also been at the forefront of disaster preparedness and recovery in many ways. The 1995 HanshinAwaji disaster, which killed more than 5500 immediately (Shinfuku 2002) and resulted in more than 40,000 injured, spurred building code reform and health system strengthening that are thought to have helped to reduce the impact of the 2011 earthquake and tsunami. In addition, the establishment of the Japanese Association for Disaster Medicine (JADM) in May 1995 as a professional association is believed to have had an important role in strengthening the health system's emergency preparedness and therefore resilience to disasters (Egawa 2014a, 2014b).

In Western Africa, the Ebola outbreak (2014-2015) devastated health facilities and people's trust in health care providers. The fragility of the health systems and the lack of resources to manage the isolation and treatment of patients overwhelmed the existing capacity of health care providers and local and national governments. The health disaster resulted in severe budget cuts to non-Ebola-related health services and a significant reduction in the use of health services owing to fears of cross-infection. As a result, more people are estimated to have died from childbirth, malaria, and AIDS, as well as other diseases (Walker et al. 2015).

Other than epidemics, disaster deaths are rarely due to infectious diseases, instead occurring due to a variety of causes that include blunt trauma, drowning, and air pollution, for instance, from forest fires or building collapses (Malilay et al. 2013). Aside from physical injury and infectious diseases, disasters can leave those affected with short- and longterm mental health consequences. Significant changes can occur rapidly in people's lives when they are exposed to extreme events and disasters. These can cause great stress to people, families, and communities because of their inherent effects, such as suffering short-term fear of death and other mental health disorders (Williams and Drury 2011). Posttraumatic stress disorder (PTSD) is the most often studied manifestation of the psychosocial stress caused by disasters, but mental health impacts also include general distress, anxiety, excessive alcohol consumption, and other psychiatric disorders (Neria and Shultz 2012).

Those with chronic diseases could have worse outcomes and many risk dying when their medication is not available or they lack access to health care. People with chronic diseases have ongoing medical needs that can easily be affected when health services are disrupted in disaster situations. While further understanding is required in this area, a recent systematic review (Ochi et al. 2014) revealed that a considerable number of patients lose their medication during evacuation, many lose essential medical aids such as insulin pens, and many do not even have a record of their prescriptions with them when evacuated. In the Philippines, during Typhoon Haiyan, the major medical and public health needs of the affected people were not injuryrelated, but the result of a lack of measures to prevent infectious diseases and the worsening of non-communicable diseases due to the lack of access to food, water, housing, and medicine (Egawa 2015).

\section{Health After the Hyogo Framework: Changing Public Health Priorities for Action in Disaster Risk Reduction}

In this section, the development of the health theme in the Annual Reports of the Secretary General (ARSG) on the implementation of the International Strategy for Disaster Reduction for the UN General Assembly (UN/GA) covering the 2005-2014 period is examined. 
In 2005, the ARSG summarized the essential elements of the Hyogo Framework for Action, but health stakeholders were not highlighted (UN/GA 2005). In 2006, the ARSG stated that the World Health Assembly urged member states to engage actively in collective measures to establish global and regional preparedness plans that integrate risk reduction into the health sector and build capacity to respond to health-related crises (UN/GA 2006). In 2008, the Hospitals Safe from Disasters campaign, supported by the World Health Organization and the World Bank, attempted to better protect the lives of patients, health staff, and the public by reinforcing the structural resilience of health facilities; ensuring that health facilities continue to function in the aftermath of disasters; and upgrading preparation and training of health workers on preparedness plans (UN/GA 2008). In 2009, UNISDR ARSG encouraged national assessments of the safety of existing education and health facilities by 2011 , and the development and implementation of concrete action plans for safer schools and hospitals by 2015 as was agreed at the Global Platform (GP) in May 2009 (UN/GA 2009).

In 2010, the UNISDR ARSG was particularly rich in capturing the impacts of disasters on health and hospitals. It stated that earthquakes in Haiti, Chile, and China have provided stark reminders of the increasing disaster risk in urban areas; and the same report predicted that it would take many decades for Haiti to recover and grow as a society and an economy because critical hospitals, other healthcare facilities, and schools were damaged or destroyed, and were consequently unable to continue service delivery to affected communities (UN/GA 2010). In 2011, the ARSG report noted that drought remains a hidden risk, poorly understood despite its impacts on human health, livelihoods, and multiple economic sectors as drought leads to stress and insecurity for rural and pastoralist populations (UN/GA 2011).

In 2012, the UNISDR ARSG mentioned the One Million Safe Schools and Hospitals initiative-through which the Secretariat works with communities, civil society organizations, governments, and the private sector to make schools and hospitals safe from disasters-and noted that the initiative had received over 200,000 pledges for safety (UN/GA 2012). Finally, in 2014, the ARSG stressed the urgent need to anticipate medium- and long-term risk scenarios and to identify concrete measures to minimize the creation of future risk, reduce existing levels of risk, and strengthen social, environmental, and economic resilience. The UN/GA observed that for the fourth consecutive year, economic losses from disasters had exceeded USD 100 billion (UN/GA 2014). These policy statements demonstrate how, over the years, UNISDR annual reports have had an increasing focus on health-related issues because of the growing concerns expressed by many stakeholders about the devastating effects of disasters on human health and well-being.

As part of the assessment of the impact and progress of the HFA, the Mid-Term Review of the Hyogo Framework for Action (UNISDR 2011) was published in 2011 and was facilitated by the UNISDR Secretariat through a participatory approach involving stakeholders at international, regional, and national levels. This report was guided by the advice of the 2009 GP for DRR, which requested a broad strategic review of the state of HFA implementation. The information that was collected was primarily of a qualitative nature, based on self-assessments and perceptions of the stakeholders involved via the HFA monitor reporting mechanism. In addition, a series of briefing papers was developed and the UNISDR Scientific and Technical Advisory Group was asked to contribute actively. In summary, this contribution stated that:

[...] recognising the importance of scientific and technical information for DRR UNISDR established a Scientific and Technical Committee in 2008 to address policy matters of a scientific and technical nature, where science is considered in its widest sense to include the natural, environmental, social, economic, health and engineering sciences, and the term 'technical' includes relevant matters of technology, engineering practice and implementation. In its reportReducing Disaster Risks through Science-issues and actions, to the GP 2009, the committee concentrated on addressing: climate change; changing institutional and public behaviour to early warnings; incorporating knowledge of the wide health impacts of disasters; improving resilience to disasters through social and economic understanding. (UNISDR 2011, p. 35)

The Mid-Term Review concluded that the implementation of HFA over the 5 years prior had generated significant international and national political momentum and action around DRR. It also underscored areas where further work was necessary to build on the positive gains of the development of the HFA in order to achieve the expected outcome of "substantial reduction of disaster losses, in the lives and in the social, economic and environmental assets of communities and countries" (UNISDR 2011, p. 69).

Although there was little on health in the HFA MidTerm Review, there was increasing interest in health-related issues in many discussions and debates around the GPs in 2011 and 2013. In part, this coincided with the Intergovernmental Panel on Climate Change (IPCC) in which UNISDR participated. In the Norway-UNISDR joint report in 2008 (Norway and UNISDR 2008), it was clearly demonstrated that there was a need for an IPCC report on disasters. This IPCC Special Report: Managing the Risks of Extreme Events and Disasters to Advance Climate Change 
Adaptation showed that much can be done to reduce the severity and frequency of extreme weather events influenced by anthropogenic climate change, through implementing sustainable development practices that aim to protect our environment and, concomitantly, improve human health and well-being (IPCC 2012). IPCC reported in 2014 that there is increased evidence that climate change is affecting many natural and human systems and poses significant risks to human health, ecosystems, infrastructure, and agricultural production (IPCC 2014). This led to a call for DRR to enable critical public policies that are informed by evidence from science and the use of tools from technology to address disaster risk (Aitsi-Selmi et al. 2015)

In summary, the Hyogo Framework for Action 2005-2015 helped to widen the remit of DRR activities beyond simply responding to disasters to include detailed risk assessment, improving early warning and response capacities, impact-based forecasting, better resource management, knowledge creation and sharing, building public commitment, and developing supportive institutional frameworks (HIS 2011). However, challenges remained in risk governance and assessment as well as monitoring, dissemination, capacity development, and shifting the culture from a hazard and response-driven culture to a riskdriven, integrated culture that encompasses the full DRR cycle from prevention to recovery and rehabilitation (IFRC 2014).

\section{Developing the Hyogo Framework for Action Successor Through International Consensus Building}

The HFA clearly suggested that successful disaster resilience requires scientific and technical capacities with inputs from physical, social, economic, health, and engineering disciplines. As the process of developing the HFA's successor began, the need for a more integrative DRR process that incorporated bottom-up and top-down actions, local scientific and technical knowledge, and a vast array of stakeholders became important (Gaillard and Mercer 2012). In this section, we review the policy development process and how the global and regional UNISDR platforms, the preparatory committees, and other international technical and policy negotiation meetings helped to shape SFDRR.

\subsection{The Global and Regional Platforms}

The GPs for DRR were held biennially from 2007 to 2013 and provided a forum for member states and other stakeholders including the scientific community and civil society organizations to assess progress on the implementation of the HFA by drawing on information from the relevant scientific and policy fora and the online Hyogo Framework Monitor (http://www.preventionweb.net/eng lish/hyogo/hfa-monitoring/national/). Regional ministerial conferences and platforms were also organized by UNISDR and its regional offices as multistakeholder fora to support the delivery of government commitments by improving coordination and implementation of DRR activities while remaining linked to national and international efforts. Only the outcomes from two recent GPs of 2011 and 2013 are discussed below.

The 2011 GP gave greater attention to people's health than the previous two GPs due to a combination of factors, including a larger number of health delegates $(>60)$ from many different countries and the establishment of a thematic platform devoted to DRR and health, which had been agreed at the 2009 GP (WHO 2009). Participants at the 2011 GP shared information on their projects and discussed a global plan of action to enhance multisectoral collaboration on DRR for health to protect lives and livelihoods (WHO 2011) and provided a launchpad for the discussions regarding the inclusion of DRR in the post-2015 development goals (WHO 2013). A joint statement on Scaling-up the Community-Based Health Workforce for Emergencies was developed by the Global Health Workforce Alliance (GHWA) together with the World Health Organization (WHO), the International Federation of Red Cross and Red Crescent Societies (IFRC), the United Nations Children's Fund (UNICEF), and the United Nations High Commissioner for Refugees (UNHCR) (GHWA et al. 2011). Speakers from WHO and partner organizations contributed to GP sessions that addressed the following issues (WHO 2011):

- Learning lessons for strengthening all-hazards preparedness arising from the global experience of a multisectoral approach to pandemic preparedness;

- Identifying the health aspects of preparedness and response to nuclear emergencies;

- Progressing the implementation of safer hospitals initiatives in more than 42 countries, which has resulted in the assessment of more than 630 health facilities assessed for their safety and ability to function in emergencies;

- Effectively restoring health services and health facilities in the recovery and reconstruction for disasters;

- Improving the flow of climate-related information between hydrometeorological services and the health sector for improved risk management and decision making in the context of the Global Framework for Climate Services; 
- Developing programs to enhance risk assessment at all levels to inform on risk management programming by communities and countries.

In the Chair's summary of the GP of 2013 emphasis was placed on targeting the root causes of risk where participants raised the need to take concrete measures to tackle risk drivers including baseline levels of disease, inadequate health services and infrastructure before, during and after disaster events, and poor water and sanitation (GPDRR 2013). Several proposed actions for health were put forward (GPDRR 2013) including: full reporting of the health burden of disasters and the consequences for community development and the systematic application of the 2005 International Health Regulations (WHO 2005). Other important themes noted by the Chair were the emphasis placed on "integrated, multisectoral approaches to DRR, and to strengthening DRR in key sectors, such as education, agriculture and health" and that "development and resilience are unlikely to be sustained unless disaster risk is explicitly addressed in all development initiatives" (GPDRR 2013, p. 2).

In addition, "The global economy's transformation over the previous 40 years was recognized as leading to a growing accumulation of disaster risk and that countless everyday local events and chronic stresses involving multiple risks are an ongoing burden for many communities. Food security, livelihoods and people's health were noted as being directly at risk in drylands and drought-prone areas subject to desertification and in small island developing states. Finally, the private sector was seen as an important piece in the risk reduction puzzle and that "resilient business and investment go hand in hand with resilient societies, ecosystems and the health and safety of employees" (GPDRR 2013, p. 3).

Statements of support for public health, science, and technology from the UNISDR Regional DRR Platforms held in 2014 in Africa (UNISDR 2014a), the Americas (UNISDR 2014b), Asia (UNISDR 2014c), Europe (UNISDR 2014d), and in the Arab League (UNISDR 2014e) have been instrumental in shaping SFDRR's commitments for DRR in public health, science, and technology.

\subsection{The Preparatory Committees}

The Preparatory Committee meetings were open to governments and nongovernmental actors (scientists, the private sector, civil society, intergovernmental organizations) and facilitated formal member state negotiations on SFDRR. Three Preparatory Committee meetings were held between July 2014 and March 2015. An example of a successful policy process is captured in the strength of the call for science and greater evidence-informed DRR. The wider DRR community worked with member states to articulate specific science requests, where science in this context refers to knowledge obtained through systematic observation, recording, testing, evaluation, and dissemination. These data are generated by physical, geographical, engineering, environmental, social, health, psychological, management, and economic sciences to name but a few (Aitsi-Selmi et al. 2015).

The science, health, and technology call was maintained by the member states at negotiations held in Geneva in June 2014, November 2014, and in January and February 2015 and finally in Sendai, Japan in March 2015. Through the various national and international DRR meetings, the call for a stronger science element in policy also received support through the Major Group on Science and Technology, organized by the International Council of Science and included many of the major science institutions of the world.

\subsection{Technical Meetings and Network Development}

Networks and international collaboration have become essential to the creation and dissemination of new knowledge (Persson et al. 2004). Linking science and decision making requires a special effort. Science panels can be used to provide advice to decision-makers such as nationallevel research councils, boards, and committees to facilitate science communication alongside the creation of public participation processes and stakeholder panels and the development of special communication materials (von Wintderfeldt 2013).

As an example of such initiatives to close the sciencepolicy gap and in an effort to promote the integration of science into the next DRR framework, Tohoku University established in 2012 the International Research Institute of Disaster Science (IRIDeS) to promote action-oriented research integrating and disseminating scientific discoveries. The institute includes a multidisciplinary disaster medical science division. In preparation for the 2015 World Conference on Disaster Risk Reduction (WCDRR) in Sendai, IRIDeS co-organized the International Symposium on Disaster Medical and Public Health Management: Review of Hyogo Framework for Action in Washington DC, May 2014. This symposium was officially supported by the Ministry of Health, Labour and Welfare of Japan. More than 120 health professionals, researchers from various organizations including UN agencies such as UNISDR, WHO, the Office for the Coordination of Humanitarian Affairs (OCHA), the World Bank, and the Pan American Health Organization (PAHO) participated.

A position paper (ISDMPHM 2014) proposed a set of recommendations reached by consensus including that the consideration of health in DRR should be imperative by promoting the mutual understanding of health and nonhealth sectors and capacity development through the 
education and training of health professionals regarding DRR to protect people's health and health infrastructure and reduce the vulnerability of communities to disasters (Egawa et al. 2014; Otomo and Burkle 2014; Sugawara and Yeskey 2014; Tomita and Ursano 2014; Pesigan and Cullison 2014; Radjak and Redmond 2014). These recommendations were disseminated through various fora including the 6th Asian Ministerial Conference on Disaster Risk Reduction (AMCDRR 2014; Chatterjee et al. 2015).

\subsection{Advocacy from the Health Sector}

WHO worked with a wide range of partners including member states through a multisectoral approach to improve health outcomes for people at risk of emergencies and disasters. WHO has been committed to providing guidance and assistance for developing country and community capacities in health and other sectors to manage the health risks associated with emergencies and disasters in an integrated manner that involves all partners and operates at all levels of research and decision making.

In the build up to WCDRR, WHO convened and participated in a number of fora to maintain the visibility of health, and influenced the policy and practice of emergency risk management for health broadly, and informed the health content of the post-2015 framework more specifically. As an example, at the $2011 \mathrm{GP}$, the issue of people's health was given greater attention due to a combination of factors, including a larger number of health delegates from many different countries and more presentations from the health sector than in previous sessions as well as two meetings of a thematic platform devoted to health (WHO 2011). In the same year, WHO also released a document that highlighted the vital role of community health workers, including volunteers, in DRR (GHWA et al. 2011), and called for governments and all partners to invest in strengthening their capacity. WHO also led the One Million Safe Hospitals and Safe Schools Campaign to make schools and hospitals safer from disasters (WHO n.d.).

WHO representatives have recognized that SFDRR is "[...]very different from what we saw in Hyogo because it's not just about protecting people's health but the recognition that health is at the very centre of DRR' and also that ' $[\mathrm{h}]$ ealth and DRR are deeply connected; healthy people are resilient people and resilient people recover more quickly from disasters" (UN News Centre 2015).

\section{SFDRR: An All-Hazards Approach}

SFDRR is a voluntary agreement adopted on 18 March 2015 by 187 UN member states after extensive negotiations at the Third World Conference on Disaster Risk
Reduction (UNISDR 2015), the successor to the HFA. It has a greater emphasis on health and gives a clearer mandate emphasizing the need for a more integrative DRR process that incorporates bottom-up as well as top-down actions, local scientific and technical knowledge, and draws attention to synergies with health, climate change, and sustainable development. This is a significant framework for health-for people's health involving all sectors and for the health sector itself-with more than 30 explicit references to health, which refer to implementation of an all-hazards approaches (Kelman 2015) and link to epidemics and pandemics in addition to the 2005 International Health Regulations (WHO 2005). This far-reaching new framework for DRR has a clear outcome, goal, seven global targets, and four priorities for action.

Five of the seven global targets are particularly relevant to health:

(a) Substantially reduce global disaster mortality by 2030 , aiming to lower average per 100,000 global mortality between 2020 and 2030 compared to 2005-2015;

(b) Substantially reduce the number of affected people globally by 2030 , aiming to lower the average global figure per 100,000 between 2020 and 2030 compared to 2005-2015;

(d) Substantially reduce disaster damage to critical infrastructure and disruption of basic services, among them health and educational facilities, including through developing their resilience by 2030 ;

(e) Substantially increase the number of countries with national and local DRR strategies by 2020; and

(g) Substantially increase the availability of and access to multi-hazard early warning (UNISDR 2015, pp. 7-8).

The following paragraphs from SFDRR include actions required by public health, which are agreed as priorities for WHO to act on in partnership with UNISDR and the UN system as well as local, national, regional, and global partners as relevant.

- In Priority 3 At National and Local Level 30(i) "Enhance the resilience of national health systems, including by integrating disaster risk management into primary, secondary and tertiary health care, especially at the local level; developing the capacity of health workers in understanding disaster risk and applying and implementing DRR approaches in health work; and promoting and enhancing the training capacities in the field of disaster medicine; and supporting and training community health groups in DRR approaches in health programmes, in collaboration with other sectors, as well as in the implementation of the 2005 International Health Regulations of the World Health Organization" (UNISDR 2015, p. 16); 
- In Priority 3 At National and Local Level 30(j) "Strengthen the design and implementation of inclusive policies and social safety-net mechanisms, including through community involvement, integrated with livelihood enhancement programmes, and access to basic health care services, including maternal, newborn and child health, sexual and reproductive health, food security and nutrition, housing and education, towards the eradication of poverty, to find durable solutions in the post-disaster phase and to empower and assist people disproportionately affected by disasters" (UNISDR 2015, p. 16);

- In Priority 3 At National and Local Level 30(k) "People with life threatening and chronic disease, due to their particular needs, should be included in the design of policies and plans to manage their risks before, during and after disasters, including having access to lifesaving services" (UNISDR 2015, p. 16);

- In Priority 3 At Global and Regional Level 31(e) "Enhance cooperation between health authorities and other relevant stakeholders to strengthen country capacity for disaster risk management for health, the implementation of the International Health Regulations (2005) and the building of resilient health systems" (UNISDR 2015, p. 17);

- In Priority 4 At National and Local Level 33(c) "Promote the resilience of new and existing critical infrastructure, including water, transportation and telecommunications infrastructure, educational facilities, hospitals and other health facilities, to ensure that they remain safe, effective and operational during and after disasters in order to provide live-saving and essential services" (UNISDR 2015, p. 18);

- In Priority 4 At National and Local Level 33(n) "Establish a mechanism of case registry and a database of mortality caused by disaster in order to improve the prevention of morbidity and mortality" (UNISDR 2015, p. 19);

- In Priority 4 At National and Local Level 33(o) "Enhance recovery schemes to provide psychosocial support and mental health services for all people in need" (UNISDR 2015, p. 19).

SFDRR strongly endorses the role of science compared to other global policy frameworks and specifically delineates the role that the UNISDR's Scientific and Technical Advisory Group (STAG) will play in implementation. The framework reflects the understanding that policies that are formulated based on scientific evidence can play an essential role in these efforts by determining disaster risk and thereby uncovering improved ways to prevent, mitigate, prepare for, recover from, and respond to disasters and therefore save lives and reduce disease related to disasters (Carabine 2015).

\section{Implementing SFDRR: The Impact on Health}

Like other wide-reaching policy frameworks, the effective implementation of SFDRR, will require the integration of momentum for action across local, national, regional, and international levels and will need to build on synergies across DRR, the Sustainable Development Goals, and the climate change agreement in 2015. Mutually beneficial capacity development and joint policy initiatives across these policy areas could considerably enhance the mainstreaming of DRR in health (WHO 2014). This should improve alignment with shifts in the health sector from a health-care focused, vertical-systems approach to an approach that strengthens health systems, promotes equity, and collaborates closely with non-health sectors to influence the wider, societal determinant of health for the health benefit of people and communities. A large part of the responsibility for linking health to DRR and implementing SFDRR with partners across the DRR community will be borne by the health sector through the leadership of the Ministries of Health in countries and the World Health Organization (UN News Centre 2015).

Working in partnership with the UNISDR STAG and linking health to DRR to implement SFDRR will have significant impact particularly when it has the following mandate in Priority 1, Paragraph 25(g):

Enhance the scientific and technical work on DRR and its mobilization through the coordination of existing networks and scientific research institutions at all levels and all regions with the support of the UNISDR Scientific and Technical Advisory Group in order to: strengthen the evidence-base in support of the implementation of this framework; promote scientific research of disaster risk patterns, causes and effects; disseminate risk information with the best use of geospatial information technology; provide guidance on methodologies and standards for risk assessments, disaster risk modelling and the use of data; identify research and technology gaps and set recommendations for research priority areas in DRR; promote and support the availability and application of science and technology to decision-making; contribute to the update of the 2009 UNISDR Terminology on DRR; use post-disaster reviews as opportunities to enhance learning and public policy; and disseminate studies (UNISDR 2015, p. 12).

The need to communicate and understand the value of SFDRR widely so that all sectors, including health actors, embrace and implement SFDRR to protect people's health from the risks of emergencies and disasters should be shared by all, if progress on the health priorities is to be 
made. The initial implementation efforts taken by stakeholders in the immediate wake of SFDRR include the following:

(1) IRIDeS committed to establishing a Global Center for Disaster Statistics in collaboration with the United Nations Development Programme (UNDP 2015). The result of a long partnership, the new centre will help deliver quality, accessible, and understandable disaster data, including health-related data, to member states as they endeavour to achieve the goals of SFDRR;

(2) A meeting organized by the Collaborating Centre for Oxford University and Chinese University of Hong Kong for Disaster and Medical Humanitarian Response (CCOUC) and the Chinese University of Hong Kong Centre for Global Health was held in Hong Kong on 23 March 2015. The purpose of the meeting was to bring together a group of local, national, and international experts on DRR representing a wide range of fields and disciplines to discuss how to consider taking forward DRR science, technology, and public health implementation in the Asia region and included a review of emergency preparedness in mainland China (CCOUC 2015); and

(3) The World Conference on Disaster and Emergency Medicine held in Cape Town, South Africa on 21-24 April 2015 whose closing statement concluded that the conference participants should endorse the precepts outlined in SFDRR, and support continuing and renewed initiatives to assist in meeting the healthrelated goals and priorities as outlined in SFDRR (WADEM 2015).

\section{Conclusions}

SFDRR includes health as an indivisible component of DRR. Its perspective is to mainstream and integrate DRR within and across all sectors, including health, and at the same time to evaluate health outcomes from DRR implementation and to align the implementation of DRR approaches with other relevant health frameworks such as the 2005 International Health Regulations (WHO 2005). This article reviewed the latest developments in DRR UNbased global policy and identifies how the public health theme has been articulated in the development of SFDRR. It also highlighted the wider role of science-a strong tradition underpinning public health-and activities that will be central to implementation. A big question remains regarding SFDRR implementation.

The means of implementation of SFDRR are outlined in its text, but need to be developed and then adapted to local requirements while simultaneously being tied to a global monitoring process that is yet to be defined. It should ideally link to the Sustainable Development Goals and climate change agreements due in 2015 (Kelman 2015; Tozier de la Poterie and Baudoin 2015). Terminology, targets, and indicators (UNISDR 2014e) and funding remain issues to be resolved.

A new phase in DRR policy and implementation is beginning and provides an opportunity to align the post2015 DRR agenda with the global public health needs of the twenty-first century through evidence-based policy and scientific activity that reflects the mandate given to the scientific community in SFDRR (see paragraph $25(\mathrm{~g})$ above). With efforts to build on synergies across health, sustainable development, and climate change, DRR can help to create convergence between global policy frameworks- $\mathrm{a}$ convergence that can be promoted and supported through better population health and well-being as a focal point and important outcome for the post-2015 UN agenda.

Acknowledgments The authors are very grateful to Jonathan Abrahams and Cathy Roth at the World Health Organization for all the work they have done to incorporate health in the Sendai Framework for DRR 2015-2030 and their comments on this and related papers on the health aspects of the SFDRR. The authors are also grateful to Public Health England for their support in carrying out this work and to Andrew Maskrey at the United Nations Office for Disaster Risk Reduction (UNISDR), for approving the use of a modified version of a figure he designed. The authors also thank Osamu Shimomura in the Japan Society for the Promotion of Science Washington Office, Washington DC; Yuichi Ono and Takako Izumi in the International Research Institute of Disaster Science, Tohoku University, Sendai, Japan; Anthony Macintyre, School of Medicine \& Health Sciences at the George Washington University, Washington DC; Charles Beadling, Metin Demir, Kevin Riley, Geoff Oravec, David Tarantino, William Lyerly, Ramey Wilson, Maysaa Mahmood, Center for Disaster and Humanitarian Assistance Medicine at Uniformed Services University of the Health Sciences, Bethesda, Maryland; and John Walsh, David L. Wessel, Children's National Health System, Washington DC for their tireless organizing effort to make the International Symposium in Washington DC possible.

Open Access This article is distributed under the terms of the Creative Commons Attribution 4.0 International License (http://creativecommons.org/licenses/by/4.0/), which permits unrestricted use, distribution, and reproduction in any medium, provided you give appropriate credit to the original author(s) and the source, provide a link to the Creative Commons license, and indicate if changes were made.

\section{References}

Aitsi-Selmi, A., K. Blanchard, D. Al-Khudhairy, W. Ammann, P. Basabe, D. Johnston, L. Ogallo, T. Onishi, et al. 2015. UNISDR STAG 2015 Report: Science is used for disaster risk reduction. http://www.unisdr.org/we/inform/publications/42848. Accessed Apr 2015.

AMCDRR (Asian Ministerial Conference on Disaster Risk Reduction). 2014. Bangkok declaration on disaster risk reduction in Asia and the Pacific 2014. http://6thamedrrthailand.net/ 
6thamcdrr/Portals/0/Final\%20Bangkok\%20Declaration\%20-6\% 20AMCDRR\%20-final\%2026\%20June-0800\%20hours.pdf. Accessed May 2015.

Carabine, E. 2015. Revitalising evidence-based policy for the Sendai framework for disaster risk reduction 2015-2030: Lessons from existing international science partnerships. PLOS Currents Disasters. doi:10.1371/currents.dis.aaab45b2b4106307ae2168a485e03b8a.

Chatterjee, R., K. Shiwaku, R. Das Gupta, G. Nakano, and R. Shaw. 2015. Bangkok to Sendai and beyond: Implications for disaster risk reduction in Asia. International Journal of Disaster Risk Science 6(2). doi:10.1007/s13753-015-0055-4.

CCOUC (The Collaborating Centre for Oxford University and Chinese University of Hong Kong for Disaster and Medical Humanitarian Response). 2015. Workshop on the implementation of post-2015 framework for disaster risk reduction in Asia. http://ccouc.org/_asset/file/report-workshop-on-sendai-frameworkccouc.pdf. Accessed May 2015.

Department for International Development. 2006. Reducing the risk of disasters-Helping to achieve sustainable poverty reduction in a vulnerable world. DFID policy paper. London: Department for International Development. http://www.preventionweb.net/files/ 2067_VL108502.pdf. Accessed May 2015.

Egawa, S. 2014a. DMAT as the first and long-lasting responder. The Hyogo framework IRIDeS review report focusing on 2011 Great East Japan Earthquake. Chapter 34, 56 and 66. http://irides. tohoku.ac.jp/media/files/the_Hyogo_Framework_IRIDeS_Revie wReport_Web_20140612\%281\%29.pdf. Accessed May 2015.

Egawa, S. 2014b. Preparedness for low-frequency and high-impact disasters from a medical perspective. The Hyogo framework IRIDeS review report focusing on 2011 Great East Japan Earthquake. Chapter 36, 58-59 and 66-67. http://irides.tohoku. ac.jp/media/files/the_Hyogo_Framework_IRIDeS_ReviewRe port_Web_20140612\%281\%29.pdf. Accessed May 2015.

Egawa, S. 2015. The second report of IRIDeS fact finding mission to Philippines. 87-106. http://irides.tohoku.ac.jp/media/files/IRIDeS_ Report_Haiyan_second_20150302.pdf. Accessed May 2015.

Egawa, S., A.G. MacIntyre, C.W. Beadling, J.T. Walsh, and O. Shimomura. 2014. International Symposium on Disaster Medicine and Public Health Management: Review of the Hyogo framework for action. Disaster Medicine and Public Health Preparedness 8(4): 357-358.

Eiser, J.R., A. Bostrom, I. Burton, D.M. Johnston, J. McClure, D. Paton, J. van der Pligt, and M.P. White. 2012. Risk interpretation and action: A conceptual framework for responses to natural hazards. International Journal of Disaster Risk Reduction 1: 5-16.

Gaillard, J.C., and J. Mercer. 2012. From knowledge to action: Bridging gaps in disaster risk reduction. Progress in Human Geography 37(1): 93-114.

GHWA (Global Health Workforce Alliance), WHO (World Health Organization), IFRC (International Federation of Red Cross and Red Crescent Societies), UNICEF (United Nations Children's Fund), and UNHCR (United Nations High Commissioner for Refugees). 2011. Scaling-up the community-based health workforce for emergencies. Scaling-up the community-based health workforce for emergencies. Joint statement by the global health workforce alliance, WHO, IFRC, UNICEF, and UNHCR. http:// www.searo.who.int/srilanka/documents/community_care_in_ emergencies.pdf?ua=1. Accessed May 2015.

GPDRR (Global Platform on Disaster Risk Reduction). 2013. Chair's summary. Fourth session of the global platform for disaster risk reduction. Geneva, 21-23 May 2013. http://www.prevention web.net/files/33306_finalchairssummaryoffourthsessionof.pdf. Accessed Apr 2015.

HIS (Helvetas Swiss Intercooperation). 2011. Disaster risk reduction \& development: Towards mainstreaming disaster risk reduction in development efforts. https://assets.helvetas.org/downloads/ 37_disasterriskreductionanddevelopmentdrr_global_red_final_ engl_a4_portrait.pdf. Accessed 18 Jan 2015.

ICSU (International Council for Science) and ISSC (International Social Science Council). 2015. Review of the sustainable development goals: The science perspective. Paris: International Council for Science (ICSU). http://www.icsu.org/publications/ reports-and-reviews/review-of-targets-for-the-sustainable-devel opment-goals-the-science-perspective-2015/SDG-Report.pdf. Accessed 19 Feb 2015.

IDNDR (International Decade for Natural Disaster Reduction). 1994. Yokohama strategy and plan of action for a safer world. Guidelines for natural disaster prevention, preparedness and mitigation. http://www.unisdr.org/we/inform/publications/8241. Accessed May 2015.

IFRC (International Federation of Red Cross and Red Crescent Societies). 2014. World disasters report: Focus on culture and risk. http://www.ifrc.org/Global/Documents/Secretariat/201410/ WDR\%202014.pdf. Accessed Jan 2015.

IPCC (Intergovernmental Panel on Climate Change). 2012. Special report: Managing the risks of extreme events and disasters to advance climate change adaptation. A special report of working groups I and II of the intergovernmental panel on climate change, ed. C.B. Field, V. Barros, T.F. Stocker, D. Qin, D.J. Dokken, K.L. Ebi, M.D. Mastrandrea, K.J. Mach, et al. Cambridge, UK: Cambridge University Press.

IPCC (Intergovernmental Panel on Climate Change). 2014. The IPCC fifth assessment report: Impacts, adaptation, and vulnerability. Working Group II. http://www.climatecouncil.org.au/uploads/ cd929c5cfed40f6d7c508dd6c1f930cf.pdf. Accessed Apr 2015.

ISDMPHM (International Symposium on Disaster Medicine and Public Health Management). 2014. Position statement. http:// www.preventionweb.net/files/38336_downloadfile13.pdf. Accessed May 2015.

Kamidohzono, S.G., O.A. Gómez, and Y. Mine. 2015. Embracing human security: New directions of Japan's ODA for the 21st century. JICA Research Institute technical report no. 94. http://jicari.jica.go.jp/publication/assets/JICA-RI_WP_No.94.pdf. Accessed Apr 2015.

Kelman, I. 2015. Climate change and the Sendai framework for disaster risk reduction. International Journal of Disaster Risk Science 6(2). doi:10.1007/s13753-015-0046-5.

Malilay, J., D. Batts, A. Ansari, C.W. Miller, and C.M. Brown. 2013. Natural disasters and environmental hazards in CDC yellowbook. http://wwwnc.cdc.gov/travel/yellowbook/2014/chapter-2the-pre-travel-consultation/natural-disasters-and-environmentalhazards. Accessed May 2015.

Murray, V., A. Aitsi-Selmi, and K. Blanchard. 2015. The role of public health within the United Nations post-2015 framework for disaster risk reduction. International Journal of Disaster Risk Science 6(1): 28-37.

Neria, Y., and J.M. Shultz. 2012. Mental health effects of Hurricane Sandy: Characteristics, potential aftermath, and response. JAMA 308(24): 2571-2572.

Norway and UNISDR (United Nations International Strategy for Disaster Reduction). 2008. Proposal for an IPCC special report on managing the risk of extreme events to advance climate change adaptation. http://www.unisdr.org/files/8150_IPCCNor wayISDRsystemProposal1.pdf. Accessed May 2015.

Ochi, S., S. Hodgson, O. Landeg, L. Mayner, and V. Murray. 2014. Disaster-driven evacuation and medication loss: A systematic literature review. PLOS Currents Disasters. doi:10.1371/cur rents.dis.fa417630b566a0c7dfdbf945910edd96.

Otomo, Y., and F.M. Burkle. 2014. Breakout session 1 summary: Frameworks and policies relating to medical preparedness and health management in disasters. Disaster Medicine and Public Health Preparedness 8(4): 359-360. 
Persson, O., W. Glanzel, and R. Danell. 2004. Inflationary bibliometric values: The role of scientific collaboration and the need for relative indicators in evaluative studies. Scientometrics 60(3): 421-432.

Pesigan, A., and T. Cullison. 2014. Breakout session 4 summary: Health infrastructure and logistics for disaster preparedness, including resources and funding. Disaster Medicine and Public Health Preparedness 8(4): 366-368.

Radjak, A., and A. Redmond. 2014. Breakout session 5 summary: Development of evidence-based technical guidance and education/training programs for the advancement of health and disaster risk management capabilities. Disaster Medicine and Public Health Preparedness 8(4): 369-371.

Rodriguez, H., T. Wachtendorf, J. Kendra, and J. Trainor. 2006. A snapshot of the 2004 Indian Ocean tsunami: Societal impacts and consequences. Disaster Prevention and Management 15(1): 163-177.

Schipper, L., and M. Pelling. 2006. Disaster risk, climate change and international development: Scope for, and challenges to, integration. Disasters 30(1): 19-38.

Scott, M., I. White, C. Kuhlicke, A. Steinführer, P. Sultana, P. Thompson, J. Minnery, E. O'Neill, et al. 2013. Living with flood risk. Planning Theory \& Practice 14(1): 103-140.

Shinfuku, N. 2002. Disaster mental health: Lessons learned from the Hanshin Awaji earthquake. World Psychiatry 1: 158-159. http:// www.ncbi.nlm.nih.gov/pmc/articles/PMC1489841/pdf/wpa0101 58.pdf. Accessed May 2015.

Sugawara, J., and K. Yeskey. 2014. Breakout session 2 summary: Health planning for all phases of a disaster including risk assessment with concern for vulnerable populations. Disaster Medicine and Public Health Preparedness 8(4): 361-362.

Tomita, H., and R.J. Ursano. 2014. Breakout session 3 summary: Psychosocial/mental health concerns and building community resilience. Disaster Medicine and Public Health Preparedness 8(4): 363-365.

Tozier de la Poterie, A., and M.-A. Baudoin. 2015. From Yokohama to Sendai: Approaches to participation in international disaster risk reduction frameworks. International Journal of Disaster Risk Science 6(2). doi:10.1007/s13753-015-0053-6.

UN (United Nations) News Centre. 2015. "Health at very center of disaster risk reduction," say UN agency officials in Sendai. http://www.un.org/apps/news/story.asp?NewsID=50328\#.VVCAavl Viko. Accessed May 2015.

UN/GA (United Nations General Assembly). 2005. Annual report of the Secretary General on the implementation of the international strategy for disaster reduction. http://www.unisdr.org/files/resolu tions/N0544902.pdf. Accessed May 2015.

UN/GA (United Nations General Assembly). 2006. Annual report of the Secretary General on the implementation of the international strategy for disaster reduction. http://www.unisdr.org/files/resolu tions/N0646059.pdf. Accessed May 2015.

UN/GA (United Nations General Assembly). 2008. Annual report of the Secretary General on the implementation of the international strategy for disaster reduction. http://www.unisdr.org/files/resolu tions/N0850245.pdf. Accessed May 2015.

UN/GA (United Nations General Assembly). 2009. Annual report of the Secretary General on the implementation of the international strategy for disaster reduction. http://www.unisdr.org/files/resolu tions/N0945314.pdf. Accessed May 2015.

UN/GA (United Nations General Assembly). 2010. Annual report of the Secretary General on the implementation of the international strategy for disaster reduction. http://www.unisdr.org/files/resolu tions/N1054565.pdf. Accessed May 2015.

UN/GA (United Nations General Assembly). 2011. Annual report of the Secretary General on the implementation of the international strategy for disaster reduction. http://www.unisdr.org/files/resolu tions/A66301E.pdf. Accessed May 2015.

UN/GA (United Nations General Assembly). 2012. Annual report of the Secretary General on the implementation of the international strategy for disaster reduction. http://www.unisdr.org/files/resolu tions/A67335E.pdf. Accessed May 2015.

UN/GA (United Nations General Assembly). 2014. Annual report of the Secretary General on the implementation of the international strategy for disaster reduction. http://www.unisdr.org/files/resolu tions/N1452549.pdf. Accessed May 2015.

UNDP (United Nations Development Programme). 2015. UNDP and Tohoku University launch "Global Centre for Disaster Statistics". http://www.undp.org/content/undp/en/home/presscenter/ pressreleases/2015/03/15/undp-and-tohoku-university-launchglobal-centre-for-disaster-statistics-.html. Accessed May 2015.

UNISDR (United Nations International Strategy for Disaster Reduction). 2005. Hyogo framework for action 2005-2015: Building the resilience of nations and communities to disasters. http:// www.unisdr.org/files/1037_hyogoframeworkforactionenglish. pdf. Accessed Apr 2015.

UNISDR (United Nations International Strategy for Disaster Reduction). 2011. The Hyogo framework for action 2005-2015 midterm review. http://www.preventionweb.net/files/18197_mid term.pdf. Accessed May 2015.

UNISDR (United Nations International Strategy for Disaster Reduction). 2012. Milestones in the history of disaster risk reductionyearly archives. http://www.unisdr.org/who-we-are/history. Accessed Apr 2015.

UNISDR (United Nations International Strategy for Disaster Reduction). 2013a. Using science for disaster risk reduction. Executive summary. http://www.unisdr.org/files/32609_stagreport2013exe cutivesummaryeng.pdf. Accessed Apr 2015.

UNISDR (United Nations International Strategy for Disaster Reduction). 2013b. Proposed elements for consideration in the post2015 framework for disaster risk reduction: By the UN special representative of the secretary-general for disaster risk reduction. http://www.preventionweb.net/files/35888_srsgelements.pdf. Accessed Feb 2015.

UNISDR (United Nations International Strategy for Disaster Reduction). 2014a. Africa Regional Platform Plenary: Stakeholder consultation reports statement from the Scientific, Technical and Academic Communities in Disaster Risk Reduction (5th African Regional Platform, Abuja, Nigeria). http://www.unisdr.org/files/37777_11. sciencetechnologyacademicgroup.pdf. Accessed Jul 2014.

UNISDR (United Nations International Strategy for Disaster Reduction). 2014b. UNISDR Regional Office for the Americas (UNISDR-Americas) and the Republic of Ecuador, through the Secretariat of Risk Management and the Ministry of Foreign Affairs. Reflections of the representatives of the scientific, technical and academic sector who participated in the Fourth Session of the Regional Platform for Disaster Risk Reduction in the Americas, 29 May 2014. http://www.eird.org/pr14-eng/docs/ science-statement-V3-English.pdf. Accessed July 2014.

UNISDR (United Nations International Strategy for Disaster Reduction). 2014c. United Nations General Assembly Third United Nations World Conference on Disaster Risk Reduction. Outcome of Sixth Asian Ministerial Conference on Disaster Risk Reduction, 22-26 June 2014, Bangkok, Thailand. A/CONF.224/PC(I)/ 11. http://6thamcdrr-thailand.net/6thamcdrr/Portals/0/Final\% 20Bangkok\%20Declaration\%20-6\%20AMCDRR\%20-final\%20 26\%20June-0800\%20hours.pdf. Accessed July 2014.

UNISDR (United Nations International Strategy for Disaster Reduction). 2014d. Second Arab Conference on Disaster Risk Reduction. City of Sharm El Sheikh, Arab Republic of Egypt, 14-16 September 2014. Sharm El Sheikh declaration on disaster risk 
reduction, 16 September 2014. http://www.unisdr.org/files/ 36370_2ndarabconferencerp2014declarationd.pdf. Accessed Feb 2015.

UNISDR (United Nations International Strategy for Disaster Reduction). 2014e. Progress and challenges in disaster risk reduction: A contribution towards the development of policy indicators for the post-2015 framework on disaster risk reduction: Summary and main findings. http://www.preventionweb.net/files/40967_ 40968progressandchallengesindisaste.pdf. Accessed May 2015.

UNISDR (United Nations International Strategy for Disaster Reduction). 2015. Sendai framework for disaster risk reduction 20152030. http://www.wcdrr.org/uploads/Sendai_Framework_for_ Disaster_Risk_Reduction_2015-2030.pdf. Accessed Apr 2015.

von Winterfeldt, D. 2013. Bridging the gap between science and decision making. Proceeding of the National Academy of Sciences of the United States of America 110(S3): 14055-14061.

WADEM (World Association of Disaster and Emergency Medicine). 2015. World Conference on Disaster and Emergency Medicine 2015 Cape Town statement. http://www.wadem.org/. Accessed May 2015.

Walker, P.G., M.T. White, J.T. Griffin, A. Reynolds, N.M. Ferguson, and A.C. Ghani. 2015. Malaria morbidity and mortality in Ebolaaffected countries caused by decreased health-care capacity, and the potential effect of mitigation strategies: a modelling analysis. Lancet Infectious Disease. doi:10.1016/S1473-3099(15)70124-6.

WHO (World Health Organization). n.d. Preparedness and risk management in health emergencies. http://www.who.int/hac/ techguidance/preparedness/en/. Accessed Apr 2015.
WHO (World Health Organization). 2005. International health regulations (2005). Second edition. http://whqlibdoc.who.int/publica tions/2008/9789241580410_eng.pdf?ua=1. Accessed May 2015.

WHO (World Health Organization). 2009. Thematic platform: Disaster risk reduction for health. http://www.who.int/hac/events/the matic_platfom_risk_reduction_health_12oct09.pdf. Accessed May 2015.

WHO (World Health Organization). 2011. Health at the Global Platform for Disaster Risk Reduction. http://www.who.int/hac/ events/disaster_reduction_2011/en/. Accessed Apr 2015.

WHO (World Health Organization). 2013. Emergency and disaster risk management for health. http://www.who.int/hac/techgui dance/preparedness/en/. Accessed May 2015.

WHO (World Health Organization). 2014. Health and disaster risk. A contribution by the United Nations to the consultation leading to the Third UN World Conference on Disaster Risk Reduction. http://www.wcdrr.org/uploads/HEALTH.pdf. Accessed Apr 2015.

Williams, R., and J. Drury. 2011. Personal and collective psychosocial resilience: Implications for children, young people and their families involved in war and disasters. In Children, and armed conflict, ed. D. Cook, J. Wall, and P. Cox. Basingstoke and New York: Palgrave McMillan.

Ye, L.H., and M. Abe. 2012. The impacts of natural disasters on global supply chains. ARTNeT Working Paper, vol. 115. http:// www.unescap.org/sites/default/files/AWP\%20No.\%20115.pdf. Accessed Jan 2015 